\title{
A '2015' Agenda for Africa: Development from a Human Perspective
}

\author{
Yehualashet Mekonen
}

\begin{abstract}
This article argues for a '2015' agenda for Africa: one that is both for and by Africa and that is seen from a human perspective. Such an agenda would not be based on 'universal' Targets. It would have a qualitative basis that would take population dynamics and child poverty into account more effectively and focus on long-term capacity building programmes in science and technology. Furthermore, it would emphasise flexibility by providing 'policy space' without conditionality.
\end{abstract}

\section{Introduction}

It is well established that human development is about expanding people's choices and the substantive freedoms - the capabilities - that enable them to lead lives that they value. Development is also about ensuring people's civil and political rights and enabling them to participate and influence decisions that affect their lives. There have been a number of initiatives aimed at bringing about development in Africa prior to the Millennium Development Declaration. Despite all these initiatives, poverty, particularly at the beginning of the millennium, was still high in Africa and access to basic needs was at the lowest level (World Bank 2008).

What makes the Millennium Declaration different from others is that it clearly recognises the fact that Africa has special needs and pledges were made to provide full support in its quest for poverty eradication and sustainable development. Despite these rhetoric commitments, at midpoint to 2015, poverty still remains high in Africa. It may even be worse due to the current food and financial crisis.

The proportion of the poor in Africa is in the range of 50-60 per cent (World Bank 2008). Although there was a decline, the proportion of people living below the poverty line in Africa is still very high. While the share of the population of sub-Saharan Africa (SSA) living on less than \$1.25-a-day (2005 PPP, purchasing power parity) has fallen from just under 58 per cent in 1990 to under 51 per cent in 2005, the number of people has risen from under 300 million in 1990 to over 380 million in 2005 (ACPF 2008a: 14). This is largely as a result of high fertility - the new poor are children - and this explains why child poverty is a very serious concern for Africa (Adem 2008).

Case studies carried out by the African Child Policy Forum (ACPF) in selected African countries showed that poverty was higher among children than adults. In Ethiopia, for instance, the incidence of poverty was three percentagepoints higher than the total incidence in 2004/05 (ACPF 2008b). All these facts indicate that high population growth largely due to high fertility, is one agenda that needs to be factored in the development discussion.

\section{Human development initiatives by and for Africa}

Human development initiative in Africa before the Millennium Declaration can fairly be categorised into two sets: the ones that were initiated by Africa and those which were initiated for Africa. Most of the initiatives by Africa were unfortunately opposed, undermined and failed largely due to a lack of support (Adedeji 2002). But, at the heart of these initiatives lie the 
Figure 1 People in sub-Saharan Africa living on less than \$1.25-a-day (2005 PPP), 1990-2005

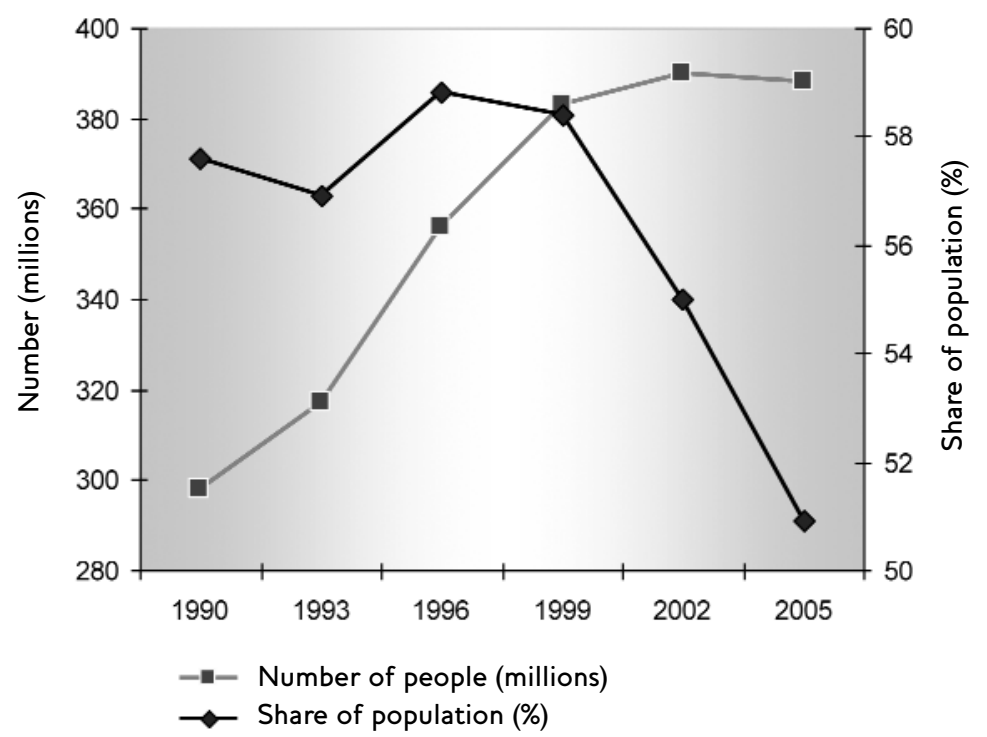

Source Based on data from World Bank, World Development Indicators (2008).

fundamental principles - self-reliance, selfsustainment and socioeconomic transformation. On the other hand, those initiatives undertaken for Africa comprise of, for example, the prescriptions of global financial institutions such as the earlier structural adjustment programmes, which did little to alleviate poverty (Baah 2003).

The Millennium Development Goals (MDGs) can be seen as an initiative that is both for, and by, Africa. It also plays a key role in monitoring development in Africa and provides a framework for international development cooperation. However, greater emphasis on localising the MDGs and African ownership and adaptation is needed in order to avoid universal Targets being meaningless in the Africa context (Easterly 2009).

Furthermore, the focus of the MDGs on quantity is misleading, and has perhaps led to negative consequences. Many SSA countries will reach, or come close to reaching, the primary school enrolment MDG - net enrolment was 66 per cent overall across SSA in 2005 (ACPF 2008b: 28). However, it is the quality, not just the quantity, of education that is an issue and poor quality of education negatively affects the poor. In SSA countries, the pupil to teacher ratio has deteriorated in countries significantly at the same time as net enrolment ratios have improved. For the world as a whole, the ratio of students to teacher is 25:1 but in SSA it is 43:1 and in some countries, it is much higher - Congo (83:1) and Chad (69:1) (ACPF 2008b: 29).

This is partly because, while it is relatively easier to increase school enrolment, it is much harder to raise the quality of schooling. Many SSA countries are lacking the basic infrastructure needed to deliver quality education. Education increases human capital, which is crucial for economic growth and poverty reduction. It is also worth noting that the emphasis on primary education has arguably reduced secondary education standards. Indeed, the cost of focusing on primary education has been the almost total neglect of secondary education. Focusing on short-term targets such as primary enrolment, may neglect the medium-term needs of a country, such as secondary enrolment. Saith (2006: 1173) argues that this 'devalues the futures of the children of the developing countries'. There is, therefore, a need to move away from a preoccupation with primary education, and more emphasis is needed on secondary and tertiary education.

\section{A '2015' agenda for Africa: development from a human perspective}

Looking at the current trend, it would be unrealistic to have universal Goals and Targets for all regions of the world. In the case of Africa, 
it seems feasible to have an extension of the present MDGs framework with additional Targets and Indicators that qualify the present ones in such a way that quality is part of the framework. Particularly in the case of access to secondary education, it is important to set Targets to ensure commitment and action in this regard. Further capacity building programmes, especially on agricultural science and technology would need to be included in the framework in view of their significance in reducing poverty and laying the foundation for sustainable development in Africa.

\section{References}

ACPF (2008a) Child Poverty in Africa: An Overview, Addis Ababa: The African Child Policy Forum ACPF (2008b) The African Report on Child Wellbeing: How Child-friendly are African Governments?, Addis Ababa: The African Child Policy Forum

Adedeji, A. (2002) 'From the Lagos Plan of Action to the New Partnership for African Development and from the Final Act of Lagos to the Constitutive Act: Wither Africa?', keynote address at the African Forum for Envisioning Africa, 26-29 April, Nairobi, Kenya

Adem, G. (2008) Child Poverty in Ethiopia, Addis Ababa: The African Child Policy Forum
Therefore, a '2015' agenda, meaning from 2010-15 as well as after-2015, for Africa, should have five principles. First, it should not be based on 'universal' Targets. Second, it should have a qualitative basis. Third, it should take into account population dynamics and child poverty. Fourth, it should emphasise long-term capacity building programmes in science and technology. Finally, it should emphasise flexibility and provide a 'policy space' for African governments, with no attached strings that would undermine their legitimate power to exercise key decisions.

Baah, A. (2003) 'History of African Development Initiatives', paper presented at the African Labour Research Network Workshop, Johannesburg, 22-23 May

Easterly, W. (2009) 'How the Millennium Goals are Unfair to Africa', World Development 37.1: $26-35$

Saith, A. (2006) 'From Universal Values to Millennium Development Goals: Lost in Translation', Development and Change 37.6: 1167-99

World Bank (2008) World Development Indicators, Poverty Data: A Supplement to World Development Indicators 2008, Washington DC: World Bank 